\title{
VALUE AT RISK AS A TOOL FOR ECONOMIC- MANAGERIAL DECISION-MAKING IN THE PROCESS OF TRADING IN THE FINANCIAL MARKET
}

\author{
Mariana Dimitrova $^{1, \mathrm{a}}$, Laurenţiu-Mihai Treapăt ${ }^{2, \mathrm{~b}}$ and Irina Tulyakova ${ }^{3, c, *}$ \\ ${ }^{1}$ Department of Administration and Management, Section "Public Administration", New Bulgarian \\ University, 21 Montevideo Str., Sofia, Bulgaria \\ ${ }^{2}$ National University of Political Studies and Public Administration, Faculty of Management, $30 \mathrm{~A}$ \\ Blvd. Expozitiei, Sector 1, Bucharest, Romania \\ ${ }^{3}$ Faculty of Economics, Saint Petersburg State University, University embankment 7-9, 199034, \\ Saint Petersburg, Russian Federation \\ am.dimitrova@nbu.bg, blaurentiu.treapat@facultateademanagement.ro, ci.tulyakova@spbu.ru \\ ${ }^{*}$ Corresponding author
}

Cite as: Dimitrova, M., Treapat, L.M., Tulaykova, I. (2021). Value at Risk as a tool for economicmanagerial decision-making in the process of trading in the financial market. Ekonomickomanazerske spektrum, 15(2), 13-26.

Available at: dx.doi.org/10.26552/ems.2021.2.13-26

Received: 17 May 2021; Received in revised form: 4 July 2021; Accepted: 25 July 2021; Available online:30 December 2021

\begin{abstract}
:
Research background: Risk is an integral part of the world of financial markets today. One of the best known and widespread methods of quantifying the risk of a securities portfolio is the concept of value at risk (VaR). The method quantifies the maximum possible loss of a securities portfolio for specific variables. We used the work of Carol Alexander as a basis for our contribution, whence we borrowed mathematical formulas and derivatives of normal linear VaR and VaR scaling.

Purpose of the article: The aim of this study is to design our own method of using the VaR calculation in the trading process and to practically verify the explanatory power of such calculation. To meet this goal, we used our own designed and adjusted formulas to calculate normal linear VaR and scaling VaR.

Methods: The purpose of these adjusted formulas is to calculate specific levels of significance of specific scenarios of the course of trading positions, which represent the probability of their occurrence. Subsequently, we used regression analysis and constructed two regression models to verify that the significance levels themselves were significant variables, and that they could explain the variability of the explanatory variable to such an extent that they could be considered as strong predictors in the trading process.

Findings \& Value added: Based on such research, we find that the resulting levels of significance of our proposed VaR calculation formulas are significant. Based on the compiled regression models, we also find that the dependence we identified is a strong one and can therefore be considered as systematic. Nevertheless, the materiality levels could explain only a small proportion of the variability of the variable being explained, and therefore could not be considered as strong predictors and thus involved in the trading process itself.
\end{abstract}

Keywords: Value at Risk, risk calculation, normal distribution, systems and econometric models 
Value at Risk as a tool for economic-managerial decision-making in the process of trading in the financial market Authors: Mariana Dimitrova, Laurenţiu-Mihai Treapăt, Irina Tulyakova

JEL Classification: C46, C58, G17

\section{Introduction}

Following the major changes in macroeconomics that took place during the 1970s, two basic directions emerged that determined the increasing level of competition and uncertainty. The deregulation of economic policy can be described first, with an appeal to market-oriented instruments. Globalisation is the second major trend and has forced companies to face the true nature of global competition. The result of both of these directions is that economic entities, but especially financial institutions, face a wide range of risks in today's house. On an international level, the last 30 years brought constant increases in the global exposures of the financial market, towards the market risk. All these dependencies and risks, if not properly known and managed, are turning into threats for the entities or persons that have exposure on the monetary market, on the foreign currency market and also on the capital market. (Treapăt and Anghel, 2016). When we talk about risk, we must be aware of its general and complex nature. Therefore, risk as such can be defined and distributed in many ways. In this paper, we will deal with only one, but very important part, of risk - financial risk. Financial risk can be described as that component of risk which is associated with losses on the capital and money markets, for example, due to a change in the price of an asset or a change in some of the determining factors. As in other areas, there is no single science in financial risk research, with the result that the terminology used is not precisely specified. (Holton, 2003)

With the lead of regulators and large international banks in the mid-1990s, almost all financial institutions now use some form of value at risk (VaR) as a risk metric. This way of calculation is actually a scientific method for historical portfolio simulation and presents the advantage that the methodology relies on a real distribution of probabilities. This almost universal acceptance of $\mathrm{VaR}$ has provoked a heated debate in professional circles. Many critics and academics have argued against metrics because they is not necessarily subadditive, which is contrary to the principle of diversification and thus to the foundations of modern portfolio theory. The VaR method is extremely difficult to define unambiguously. (Agliardi, 2018)

This problem stems from the ambiguity of what VaR should represent in academia and the financial world. (Echaust and Just, 2020) In other words, even the widespread adoption of the VaR method did not unify risk measurement to the extent that IAS / IFRS standards brought to accounting. We can therefore define the $\mathrm{VaR}$ method in various ways; the most common are as follows:

The 1996 Risk Metrics Technical Document: 'Value-at-risk measures the maximum potential change in the value of a portfolio of financial instruments with a given probability within a predetermined time horizon. VaR answers the question: how much can I lose with $x \%$ probability in a given time horizon?'

P. Jorion: 'VaR summarises the worst loss over a given time horizon in a given confidence interval'. (Jorion, 2001)

P. Embrechts: 'VaR is a percentile (quantile) of the distribution of profits and losses with the property that [,] with a small exogenously determined probability, we will lose VaR and more within a fixed time horizon'. (Embrechts, 2001)

C. Butler: 'VaR measures the worst expected loss that an institution faces in a given time interval, under normal market conditions, at a given level of materiality. VaR assesses this risk using statistical and simulation models that are developed to determine the volatility of the bank's portfolio in question'. (Butler, 1998) 
G.A. Holton: 'VaR is a risk measure category. As each risk measurement category, we define VaR in terms of a risk metric that supports and interprets VaR measurement'. (Holton, 2003)

$\mathrm{VaR}$ calculation is usually more complex than calculation using traditional risk metrics, as it depends on the multidimensional distribution of risk factor returns, the dynamics of this distribution, as well as the mapping of portfolio risk factors. (Halkos and Tsirivis, 2019)

Mathematical models that are used to derive risk metrics from this model (e.g. using some type of simulation procedure) are referred to as the resolution method. Although VaR and related measures, such as Extract, Transform and Load system (ETL) and reference VaR, are currently adopted almost universally, the development of risk assessment in the financial industry has been based on various traditional risk metrics that continue to be used in conjunction with VaR. (Cisko and Kliestik, 2013)

Generally, some traditional risk metrics only measure sensitivity to a risk factor, while ignoring the risk of the factor itself. For example, the equity portfolio beta or the delta and gamma options portfolios are examples of price sensitivity. (Crespi and Mastrogiacomo, 2020)

Other traditional risk metrics measure risk against a benchmark. One of the main activities of banks and other financial institutions is to take risks (because they know or should know how to manage them) in exchange for premiums paid by clients. This is traditionally the main source of profit for retail and commercial banks. An example is the listing of option contracts in which banks generate a profit on the option premium. However, the search for profitable business opportunities through increased return on investment is not their primary focus, it is the subject and role of portfolio management. (Molino and Sala, 2021)

The asset management business of a large investment bank strives for an excellent return on investment, whereas banks' primary concern is to manage their risks. A very important risk management decision for banks is whether to retain or hedge at least some of the risks. (Slim et al., 2020)

The basis for such a decision is the manager's ability to measure these risks. Market risks are often measured in the very short term; thus, banks have the opportunity to hedge their risks. It is also standard in the short term to assume that the expected return on a financial asset is a risk-free rate of return. (Del Brio et al., 2020; Thavaneswaran et al., 2020)

However, risk is associated with an unexpected return, which, here, means a deviation of the return from its expected value. Instead of fully hedging all risks, traders are usually required to manage their positions such that their overall risk remains within limits. This limit may change over time. (Rige et al., 2020)

An important aspect of risk control is setting appropriate risk limits for individual traders. If a market is highly volatile, the risk limits in such a market should be increased. Traders cannot influence risk factor risk; however, they can monitor risk factor volatility and manage their systematic risk by adjusting their exposure to the risk factor. Due to significant problems, most large banks have replaced or expanded the traditional approach. (Le, 2020)

Many large banks and financial institutions currently set and manage traders' limits using VaR. New banking regulations for market risk, introduced in 1996, foreshadowed a 'more holistic' approach to risk management. Market VaR includes risk that arises from risk factors as well as sensitivity to these factors. Consequently, most large banks have taken VaR, or related measures, as conditional VaR, to assess the risks of their operations at every level, from that of the trader to the decisions and risk management of the bank as a whole. (Bi and Zhu, 2020) 
Bank risks are measured, by default, at the bottom. This means that risks are first identified at the level of individual trading positions. . As presented Treapăt and Anghel (2016), the exposure to such risk may occur as a result of some speculative positions deliberately taken by the bank (own account trading), or may derive from the market creator activities for the clients (dealing). The modification of the conditions on the financial markets may affect the bank through the main three interdependent but separately managed transmission channels. These are: the variation of the evolution trend and of the level of the interest rates, the variation of the foreign currency exchange rate and consequently, of the local currency value of the various assets and liabilities expressed in foreign currency and the variation of the financial assets rate that may affect the market value of the titles portfolio and the value of the titles issued by the bank (bonds or shares). The financial - banking markets developed also in Eastern Europe together with the globalization process, the derivate financial instruments began to be more intensively used, either for protection reasons against the adverse reactions resulted from the market evolution, or purely speculative, trying to obtain advantages depending on the conditions existing on the market. In our opinion, particularly the usage of such financial instruments induces additional risks at the banks' level, at a systemic level and then, until the crisis unleashes, there is just one single step left. Subsequently, these positions are integrated into a specific portfolio, and thus we obtain a degree of portfolio risk. One of the main reasons that prompted the rapid development of risk assessment in banking is the impetus provided by the new banking regulations in the 1990s. Regulators have begun to require individual banks and financial institutions to measure their risks as accurately as possible each day and to maintain an adequate level of capital in relation to those risks. (Meng and Taylor, 2020)

$\mathrm{VaR}$ therefore represents a loss at present value due to market movements, which we are reasonably certain will not be exceeded if the portfolio is held statically for a period of time. We cannot say anything about the profit and loss $(\mathrm{P} \& \mathrm{~L})$ portfolio because it is a random variable; however, we can associate a level of confidence with any loss. For example, the 5\% daily VaR, which corresponds to a $95 \%$ confidence level, is the level of loss we expect at a frequency of $5 \%$ when the current portfolio is held for 24 hours.

The fact that the latest research on this metric reflects current developments in the financial markets is proof that the issue of $\mathrm{VaR}$ is constantly relevant. This is evidenced by the fact that some of the research is even conducted in the emerging market of crypto currencies. (Liu et al., 2020; Silahli et al., 2021; Tan et al., 2021)

\section{Methodology}

As a basis for further use, practical application, and calculation of the probability of collapse of individual trading positions, which we will address in the practical part, we used the formula for calculating normal linear VaR and scaling VaR, which is found in the book, 'Market Risk Analysis Vol. IV "Value-at-Risk Methods"', published in 2008 by Carol Alexander.

\subsection{Normal linear VaR}

In her derivative, Carol Alexander (2008) assumes that we try to measure VaR without assigning VaR to other risk factors. For simplicity, it assumed that the discounted returns for day $\mathrm{h}$ were identically and independently distributed (i.i.d) and had a normal distribution. To simplify registration, she used $\mathrm{X}$ to indicate revenue, reducing time and risk. 


$$
X^{i . i . d} \sim N\left(\mu, \sigma^{2}\right)
$$

Carol Alexander (2008) continued to derive a formula for $X_{\alpha}, \alpha$ quantile yield, i.e. such a yield that $P\left(X<X_{\alpha}\right)=\alpha$. Then $100_{\alpha} \% \mathrm{VaR}$, expressed as a percentage of the portfolio value, will be minus this $\alpha$ quantile yield.

$$
P\left(X<X_{\alpha}\right)=P\left(\frac{X-\mu}{\sigma}<\frac{X_{\alpha}-\mu}{\sigma}\right)=P\left(Z<\frac{X_{\alpha}-\mu}{\sigma}\right)
$$

where $Z \sim N(0,1)$. Thus, if $P\left(X<X_{\alpha}\right)=\alpha$, then,

$$
P\left(Z<\frac{X_{\alpha}-\mu}{\sigma}\right)=\alpha
$$

But by definition, $\mathrm{P}\left(\mathrm{Z}<\Phi_{-1}(\alpha)\right)=\alpha$, thus:

$$
\frac{X_{\alpha}-\mu}{\sigma}=\Phi^{-1}(\alpha)
$$

where $\Phi$ is the standard function of the normal distribution. However, according to the definition of $\mathrm{X}_{\alpha}=-\mathrm{VaR}_{\alpha}$ and $\Phi_{-1}(\alpha)=-\Phi_{-1}(1-\alpha)$ according to the symmetry of the standard normal distribution, Carol Alexander (2008) subsequently substituted them into the above formula and created an analytical formula for VaR for the portfolio with an i.i.d. normal yield.

$$
\operatorname{VaR}=\Phi^{-1}(1-\alpha) \sigma-\mu
$$

\subsection{Scaling VaR}

$\mathrm{VaR}$ is often measured in the short term, such as the 1-day $\mathrm{VaR}$, and then adjusted to represent the $\mathrm{VaR}$ in the longer term. We dealt with the short-term VaR calculation in detail in the previous subchapter (Brandi and Di Matteo, 2021). How should VaR that is estimated at one risk horizon be scaled to one that is measured at another risk horizon? Carol Alexander (2008) also asked this question and answered it as follows:

- the average of day $h$ is $h \times$ daily average, $\mu \mathrm{h}=\mathrm{h} \mu_{1}$

- day deviation $\mathrm{h}$ is $\mathrm{h} \times$ daily deviation, $\sigma^{2} \mathrm{~h}=\mathrm{h} \sigma_{1}{ }^{2}$

$$
\operatorname{VaR}_{1, \alpha}=\Phi^{-1}(1-\alpha) \sigma_{1}-\mu_{1}
$$

where $\mu_{1}$ and $\sigma_{1}$ are yield expectations and the standard deviation of normally distributed daily returns, respectively. We can now use the logarithmic approximation to the daily discounted yield.

$$
X_{1 t} \approx \frac{P_{t+1}-P}{P_{t}} \approx \ln \left(\frac{P_{t+1}}{P_{t}}\right)
$$

We can now approximate the logarithmic yield of day h to the current yield of day $h$ and deduce that it is (approximately) normally distributed. Then, the $\mathrm{VaR}$ on day $\mathrm{h}$ is given by approximation as follows:

$$
\operatorname{VaR}_{h, \alpha} \approx \Phi^{-1}(1-\alpha) \sqrt{h} \sigma_{1}-h \mu_{1}
$$


As a result of the calculation of scaled VaR, similar to normal linear VaR, it is the maximum possible loss of the securities portfolio at a given market volatility, average return, and at a selected level of significance, $\alpha$, in a given multi-day time horizon.

\section{Results}

The aim of our study is to explore the possibilities of $\mathrm{VaR}$ calculation in the process of trading on the financial market. $\mathrm{VaR}$ calculation is a portfolio risk prediction method that, by its very nature, offers the trader or investor a prediction of the maximum possible loss for a particular securities portfolio at specific market characteristics and at a specific level of materiality that defines the probability of a given loss. Based on the nature of trading as such, and the trading system we have proposed, we have proposed the following procedure. We have adjusted the formula for calculating normal linear VaR so that the result of such a calculation is not the amount of the financial loss, but the level of significance at which such a loss occurs. The logic of such a calculation lies in the fact that, based on the setting of the risk management of the trading system, we know the monetary expression for the maximum loss, which we accept in the event of unstoppable developments, and therefore the probability with which such a result will occur is unknown. This logic is based directly on the assumption of the distribution function of the normal distribution. Verification of the normal distribution of values is a basic prerequisite for the application of the $\mathrm{VaR}$ method. For a better understanding and interpretation of the resulting values, we present the following graph.

Figure 1: Normal distribution of values

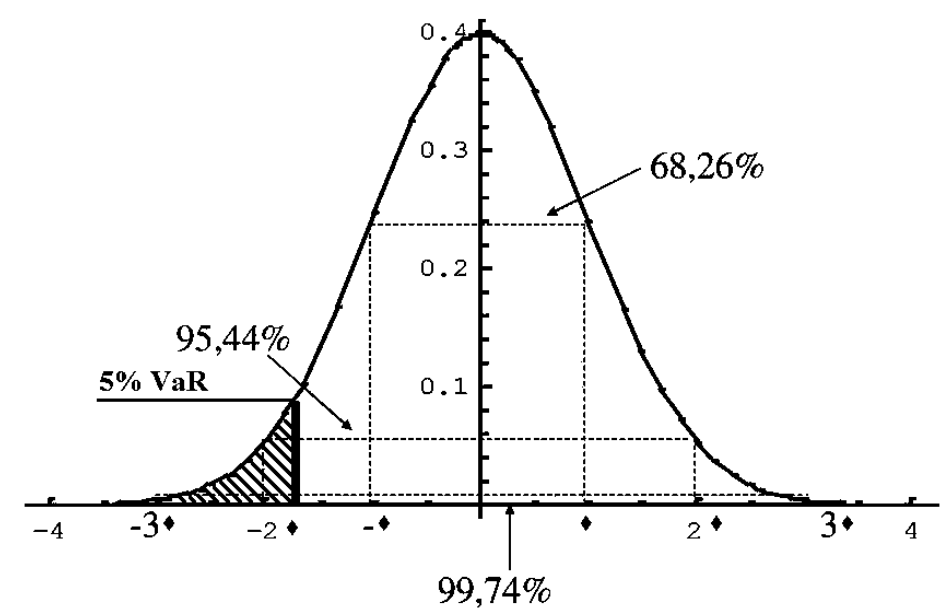

Source: Processed by authors

In this graph we can see the standard normal distribution of the values of their mean value, consisting of the distribution of the individual values +-3 standard deviations from this mean. If we talk about the VaR method, then we must specify to which quantity; in this case, the assumption of a normal distribution applies. (Josaphat and Syuhada, 2021; Kabaila and Mainzer, 2018)

From the calculation formula, clearly, this method assumes a normal distribution of the expected return on assets. Since in our case these are the average daily returns of the financial instrument, SPY ETF, and we know that the sum of a large number of independent random variables with finite mean and variance has an asymptotically normal distribution, we can refer to the central limit theorem and consider the average returns on this instrument as 
normally distributed. This approach is used in practice; if the investigated random variables in individual experiments do not have a normal distribution, then their sum is treated, with a sufficiently large number, as a normally distributed random variable.

\subsection{Transformation of the calculation formula of normal linear VaR and scaling VaR}

We used the following mathematical formulations as a basis for adjusting the formulas for calculating the significance level:

$$
\operatorname{VaR}=\Phi^{-1}(1-\alpha) \sigma-\mu
$$

The result of the calculation of normal linear $\mathrm{VaR}$ is the maximum possible loss for a securities portfolio at a given market volatility, average return, and at a selected level of significance $\alpha$. We chose this calculation if we wanted to quantify the level of significance within one day.

$$
\operatorname{VaR}_{h, \alpha} \approx \Phi^{-1}(1-\alpha) \sqrt{h} \sigma_{1}-h \mu_{1}
$$

As a result of the calculation of scaled VaR, similar to normal linear $\mathrm{VaR}$, it is the maximum possible loss for the securities portfolio at a given market volatility, average return, and at a selected level of significance, $\alpha$, in a given multi-day time horizon. We chose this calculation as the basis for calculating the level of significance in the event of a need for a calculation in a multi-day horizon.

Based on the above mathematical formulas, we proposed the following adjustments:

$$
\Phi\left(\frac{V a R+\mu_{1}}{\sigma_{1}}\right)=1-\alpha
$$

where $\quad$ VaR size of the loss of the position

$\sigma_{1}$ market volatility

$\mu_{1}$ expected average return on the asset

1- $\alpha$ probability of occurrence of the phenomenon

$\Phi$ distribution function of the normal distribution

$$
\Phi\left(\frac{\operatorname{VaR}_{h, \alpha}+h, \mu_{h}}{\sqrt{h} \sigma_{1}}\right) \approx 1-\alpha
$$

where $\quad \mathrm{VaR}_{\mathrm{h}, \alpha}$ size of the loss of the position

$\sigma_{\mathrm{h}}$ market volatility

$\mu_{\mathrm{h}}$ expected average return on the asset

1- $\alpha$ significance level (probability)

$\Phi$ distribution function of the normal distribution

\subsection{Application and calculations of individual significance levels}

Based on the above mentioned formulas, we should be able to quantify the level of significance of $\alpha$ and thus the probability of occurrence. However, if we look at Figure 1, we must realise that the variable, 1- $\alpha$, expresses to us the percentages for all scenarios, which are equal to our loss and better. Therefore, if we want to identify the probability that represents the loss scenarios, this probability corresponds directly to the value of the coefficient, $\alpha$. We have retrospectively applied this calculation with this interpretation to all trades in the trading 
system. The purpose of this calculation was to identify any explanatory power that could be used in the trading system as a prediction of future price developments. For the needs of the application of this calculation, we chose the application on the results of the trading system with the optimal output price due to the larger number of files.

For the needs of the research of the proposed calculation formula, we used the results of the real trading system. The preliminary results were as follows. Based on the measured data, we can assert the following: Within the examined period, 1.1.2020 to 31.12.2020, the 30minute chart of the financial instrument, SPY ETF, based on the above-mentioned application rules, identified 45 situations suitable for the application of the Volume profile method. In 45 situations, the Volume profile method offered us 37 predictions, and in 8 cases there was no market situation that would result in a prediction formulation (although the price started the correction but did not leave the value range), which represented approximately $82.2 \%$ of the total application cases. Of these 37 predictions, 26 were predictions (approximately 70.3\%) of the end of the price correction and the continuation of the UP trend, while the remaining 11 (29.7\%) predictions were of the opposite situation, namely, the end of the correction and the subsequent price drop. This fact reflects the market situation within the price development of the SPY ETF when a long-term growing trend has been recorded on this instrument since its inception (we have identified the primary trend as a constant). The structure of the secondary trend within the identified 45 situations of application of the present method corresponded to the ratio 34:11, which represented the UP trend identified in 34 cases $(75.6 \%$ representation of the UP trend within the secondary trends) and the Down trend in the other 11 cases $(24.4 \%$ Down trend representation within secondary trends). Regarding the structure of the current trends within the examined situations, we have identified a relatively evenly represented occurrence of both trends. In $25(55.6 \%)$ cases, it was an identified UP trend, while in 20 $(44.4 \%)$ cases, it was a down trend. Regarding the very success of the individual predictions of the Volume profile method, we can assert the following: Out of the total number of 37 predictions, 26 were successful, which represented a $70.27 \%$ success rate. However, it should be noted that the Volume profile method achieved such a result in compliance with the established application rules, at a pre-identified time interval of a specific financial instrument (in our case, the SPY ETF). The remaining 11 (29.73\%) predictions did not correspond to the real market reaction, and we therefore consider them unsuccessful. We set the criterion for the identification of successful predictions in such a way that we considered as a successful prediction only one that coincided with the direction of the real price reaction and this price reaction achieved at least a return to the value area of the Volume profile method (Tables 1 and 2).

Table 1: Average characteristics of trades

\begin{tabular}{lll}
\hline & Profitable predictions & Losing predictions \\
\hline Average time interval & 88.31 & 61.17 \\
Average price interval in USD & 13.22 & 11.29 \\
& $18 \mathrm{UP}$ & $8 \mathrm{UP}$ \\
Dirrection of prediction & $8 \mathrm{Down}$ & 3 Down \\
The average number of candles outside the value range & 5.5 & 4 \\
\hline
\end{tabular}




\begin{tabular}{lll}
\hline The average size of an Inflection Candle in USD & 2.05 & 1.63 \\
The average reaction time in the number of candles & 122.19 & 93.08 \\
Average volatility (previous trading day) & 0.2629 & 0.1792 \\
\hline
\end{tabular}

Source: Processed by authors

Table 2: Results of calculation of individual significance levels

\begin{tabular}{|c|c|c|c|c|c|c|c|}
\hline \multirow{2}{*}{$\begin{array}{l}\text { Direction } \\
\text { UP }\end{array}$} & \multirow{2}{*}{$\begin{array}{l}\text { Volatility } \\
0.1316\end{array}$} & \multicolumn{2}{|c|}{ Loss in USD } & \multirow{2}{*}{$\begin{array}{l}\mathbf{1}-\boldsymbol{\alpha} \\
(\mathbf{1} \text { day })\end{array}$} & \multirow{2}{*}{$\begin{array}{l}\alpha \\
\text { (1 day) } \\
0.46909\end{array}$} & \multirow{2}{*}{$\begin{array}{l}\begin{array}{l}1-\alpha \\
\text { (h-day) }\end{array} \\
0.51122\end{array}$} & \multirow{2}{*}{$\begin{array}{l}\begin{array}{l}\alpha \\
\text { (h-day) }\end{array} \\
0.48878\end{array}$} \\
\hline & & $\$$ & 2320.00 & & & & \\
\hline $\mathbf{U P}$ & 0.1217 & $\$$ & 26050.69 & 0.56998 & 0.43002 & 0.52452 & 0.47548 \\
\hline UP & 0.0901 & $\$$ & 30100.01 & 0.54671 & 0.45329 & 0.51405 & 0.48595 \\
\hline $\mathbf{U P}$ & 0.0973 & $\$$ & 34778.76 & 0.54274 & 0.45726 & 0.51335 & 0.48665 \\
\hline UP & 0.0992 & $\$$ & 33971.89 & 0.54048 & 0.45952 & 0.51277 & 0.48723 \\
\hline UP & 0.0992 & $\$$ & 33183.74 & 0.55461 & 0.44539 & 0.51725 & 0.48275 \\
\hline $\mathbf{U P}$ & 0.0995 & $\$$ & 32413.88 & 0.56448 & 0.43552 & 0.52042 & 0.47958 \\
\hline Down & 0.1139 & $\$$ & 31661.88 & 0.58054 & 0.41946 & 0.52735 & 0.47265 \\
\hline Down & 0.1239 & $\$$ & 30927.32 & 0.59123 & 0.40877 & 0.53236 & 0.46764 \\
\hline Down & 0.1427 & $\$$ & 30209.81 & 0.58650 & 0.41350 & 0.53290 & 0.46710 \\
\hline Down & 0.1565 & $\$$ & 29508.94 & 0.61131 & 0.38869 & 0.54453 & 0.45547 \\
\hline Down & 0.1793 & $\$$ & 34095.81 & 0.61531 & 0.38469 & 0.54940 & 0.45060 \\
\hline Down & 0.2458 & $\$$ & 33304.79 & 0.68831 & 0.31169 & 0.59617 & 0.40383 \\
\hline Down & 0.3767 & $\$$ & 32532.11 & 0.61279 & 0.38721 & 0.56981 & 0.43019 \\
\hline Down & 0.3895 & $\$$ & 31777.37 & 0.61602 & 0.38398 & 0.57304 & 0.42696 \\
\hline Down & 0.4373 & $\$$ & 31040.13 & 0.56414 & 0.43586 & 0.54252 & 0.45748 \\
\hline UP & 0.4526 & $\$$ & 35865.01 & 0.51561 & 0.48439 & 0.51050 & 0.48950 \\
\hline UP & 0.4596 & $\$$ & 35032.94 & 0.53464 & 0.46536 & 0.52350 & 0.47650 \\
\hline UP & 0.468 & $\$$ & 34220.18 & 0.52088 & 0.47912 & 0.51429 & 0.48571 \\
\hline UP & 0.4903 & $\$$ & 33426.27 & 0.51603 & 0.48397 & 0.51123 & 0.48877 \\
\hline UP & 0.4912 & $\$$ & 38622.05 & 0.51032 & 0.48968 & 0.50723 & 0.49277 \\
\hline UP & 0.4705 & $\$$ & 44625.46 & 0.50944 & 0.49056 & 0.50647 & 0.49353 \\
\hline UP & 0.337 & $\$$ & 51562.05 & 0.51499 & 0.48501 & 0.50870 & 0.49130 \\
\hline UP & 0.236 & $\$$ & 50365.81 & 0.54657 & 0.45343 & 0.52266 & 0.47734 \\
\hline $\mathbf{U P}$ & 0.2239 & $\$$ & 49197.32 & 0.52639 & 0.47361 & 0.51249 & 0.48751 \\
\hline Down & 0.2085 & $\$$ & 48055.94 & 0.56445 & 0.43555 & 0.52953 & 0.47047 \\
\hline Down & 0.2084 & $\$$ & 46941.04 & 0.54676 & 0.45324 & 0.52138 & 0.47862 \\
\hline UP & 0.206 & $\$$ & 45852.01 & 0.54098 & 0.45902 & 0.51862 & 0.48138 \\
\hline UP & 0.1993 & $\$$ & 52979.25 & 0.52912 & 0.47088 & 0.51301 & 0.48699 \\
\hline UP & 0.2039 & $\$$ & 61214.34 & 0.53394 & 0.46606 & 0.51534 & 0.48466 \\
\hline UP & 0.1848 & $\$$ & 59794.17 & 0.54752 & 0.45248 & 0.52047 & 0.47953 \\
\hline
\end{tabular}




\begin{tabular}{llllllll}
\hline UP & 0.1842 & $\$ 58406.94$ & 0.54298 & 0.45702 & 0.51847 & 0.48153 \\
UP & 0.1825 & $\$$ & 67485.72 & 0.52674 & 0.47326 & 0.51143 & 0.48857 \\
$\mathbf{U P}$ & 0.1776 & $\$$ & 77975.70 & 0.52498 & 0.47502 & 0.51053 & 0.48947 \\
$\mathbf{U P}$ & 0.1746 & $\$$ & 76166.66 & 0.53115 & 0.46885 & 0.51303 & 0.48697 \\
$\mathbf{U P}$ & 0.1739 & $\$$ & 74399.60 & 0.52522 & 0.47478 & 0.51052 & 0.48948 \\
$\mathbf{U P}$ & 0.1721 & $\$$ & 85964.27 & 0.52476 & 0.47524 & 0.51028 & 0.48972 \\
\hline
\end{tabular}

Source: Processed by authors

Since we did not have a tool that could effectively predict the duration of the position, we performed both calculations within a time horizon of 1 day and then compared their results. Subsequently, we performed a regression analysis of the data obtained, the aim of which was to identify an interdependence between the thus quantified values of the $\alpha$ coefficients, which should represent the percentage of scenarios that were worse than our maximum loss.

\subsection{Regression model of $\alpha$ 1-day VaR calculation}

Explained variable $\boldsymbol{Y}$ - success of individual positions

Explanatory variables $\boldsymbol{X}$ - the value of the resulting variable, $\alpha$, for a 1-day calculation

Table 3: Regression model of a 1-day VaR calculation

\begin{tabular}{|c|c|c|c|c|c|c|c|c|}
\hline \multicolumn{9}{|c|}{ Regression Statistics } \\
\hline Multiple R & 0.38890 & & & & & & & \\
\hline R Square & 0.15124 & & & & & & & \\
\hline Adj. R Square & 0.12699 & & & & & & & \\
\hline Standard & 0.45220 & & & & & & & \\
\hline Observations & 37.0000 & & & & & & & \\
\hline \multicolumn{9}{|l|}{ ANOVA } \\
\hline & $d f$ & $S S$ & $M S$ & $\boldsymbol{F}$ & Sig. $F$ & & & \\
\hline Regression & 1.00000 & 1.27535 & 1.27535 & 6.23680 & 0.01736 & & & \\
\hline Residual & 35.00000 & 7.15708 & 0.20449 & & & & & \\
\hline \multirow[t]{2}{*}{ Total } & 36.00000 & 8.43243 & & & & & & \\
\hline & Coefficients & $\begin{array}{l}\text { Standard } \\
\text { Error }\end{array}$ & $t$ Stat & $P$-value & $\begin{array}{l}\text { Lower } \\
95 \%\end{array}$ & $\begin{array}{l}\text { Upper } \\
95 \%\end{array}$ & $\begin{array}{l}\text { Lower } \\
95.0 \%\end{array}$ & $\begin{array}{l}\text { Upper } \\
95.0 \%\end{array}$ \\
\hline Intercept & -1.84791 & 0.88377 & -2.09095 & 0.04386 & -3.64205 & -0.05377 & -3.64205 & -0.05377 \\
\hline a (1-day) & 4.91664 & 1.96874 & 2.49736 & 0.01736 & 0.91989 & 8.91338 & 0.91989 & 8.91338 \\
\hline
\end{tabular}

Source: Processed by authors

Based on the above calculation of the regression model of the given variables, by comparing the P-value of the explanatory variable with the level of significance, we have identified a significant variable. Based on the coefficient of determination, the regression model compiled in this way explains $15.124 \%$ of the variability of the variable Y. Thus, the variable, $\alpha$, explains $15.124 \%$ of the variability of the resulting success of individual positions; the rest are unknown effects.

\subsection{Regression model of $\alpha$ h-day VaR calculation}

Explained variable $\boldsymbol{Y}$ - success of individual positions

Explanatory variables $\boldsymbol{X}$ - value of the resulting variable, $\alpha$, for the h-day calculation

Table 4: Regression model of $\alpha$ h-day VaR calculation 


\begin{tabular}{|c|c|c|c|c|c|c|c|c|}
\hline Multiple R & 0.37815 & & & & & & & \\
\hline R Square & 0.14300 & & & & & & & \\
\hline $\begin{array}{l}\text { Adj. R } \\
\text { Square }\end{array}$ & 0.11851 & & & & & & & \\
\hline Standard & 0.45439 & & & & & & & \\
\hline Observations & 37.00000 & & & & & & & \\
\hline \multicolumn{9}{|l|}{ ANOVA } \\
\hline & $d f$ & $S S$ & $M S$ & $F$ & Sig. $F$ & & & \\
\hline Regression & 1.00000 & 1.20584 & 1.20584 & 5.84016 & 0.02102 & & & \\
\hline Residual & 35.00000 & 7.22659 & 0.20547 & & & & & \\
\hline \multirow[t]{2}{*}{ Total } & 36.00000 & 8.43243 & & & & & & \\
\hline & Coefficients & $\begin{array}{l}\text { Standard } \\
\text { Error } \\
\end{array}$ & $t$ Stat & $P$-value & Lower 95\% & $\begin{array}{l}\text { Upper } \\
95 \%\end{array}$ & $\begin{array}{l}\text { Lower } \\
95.0 \% \\
\end{array}$ & $\begin{array}{l}\text { Upper } \\
95.0 \% \\
\end{array}$ \\
\hline Intercept & -4.00752 & 1.80524 & -2.21994 & 0.03300 & -7.67234 & -0.34270 & -7.67234 & -0.34270 \\
\hline a (h-day) & 9.15906 & 3.78999 & 2.41664 & 0.02102 & 1.46496 & 16.85315 & 1.46496 & 16.85315 \\
\hline
\end{tabular}

Source: Processed by authors

As in the previous case, based on the above calculation of the regression model of the given variables, by comparing the P-value of the explanatory variable with the level of significance, we identified a significant variable. The regression model compiled in this way explains $14.3 \%$ of the variability of the variable, Y, based on the coefficient of determination. Thus, the variable, $\alpha$, explains only $14.3 \%$ of the variability of the resulting success of individual positions, while the rest are unknown effects.

\section{Discussion}

As already mentioned, VaR calculation is a portfolio risk prediction method that, by its very nature, offers a trader or investor a prediction of the maximum possible loss for a particular securities portfolio at specific market characteristics and at a specific level of materiality that defines the probability of a given loss. (Dong et al., 2020; Mitic et al., 2020; Zhang et al., 2019; Bucher et al., 2020; Corbetta and Peri, 2018; Leippold and Vasiljevic, 2020)

Based on the nature of trading, and on our proposed trading system, we proposed a procedure based on adjusting the formula for calculating normal linear VaR such that the result of such a calculation was not the amount of financial loss but the level of significance at which such a loss occurred. Del Brio et al., 2020; Chen et al., 2019)

The logic of such a calculation lies in the fact that, based on the setting of the risk management of the trading system, we know the monetary expression for the maximum loss, which we accept in the event of unstoppable developments, and therefore the probability with which such a result will occur is unknown. This logic is based directly on the assumption of the distribution function of the normal distribution. Verification of the normal distribution of values is a basic prerequisite for the application of the VaR method. (Ahmadi-Javid and Fallah-Tafti, 2019)

As a result of this adjustment, the formula for calculating the normal linear VaR for calculating the significance level at the 1-day horizon and the scaling VaR for calculating the significance level at the multi-day horizon was adjusted. Subsequently, we subjected the data obtained and data on the success of individual positions to regression analysis, the aim of which was to identify a dependence between both individual levels of significance and the results of individual positions as explanatory variables. Based on the results of the regression analyses of the characteristics mentioned, we concluded that the variables, $\alpha$, obtained in this 
way could be considered as significant variables in relation to the results of individual positions. However, despite such a finding, their coefficient of determination is not high enough for us to consider this variable as a relevant characteristic to which we would subject trading activities within the trading system. In the case of calculating the variable, $\alpha$, based on the normal linear VaR calculation formula, this variable can explain $15.124 \%$ of the variability of the trading system result. In the case of calculating the variable, $\alpha$, based on the scaling VaR calculation formula, this variable can explain $14.3 \%$ of the variability of the trading system result.

The eloquence of the case study calculations presented is most likely the strongest argument of the current paper because it can be understood by readers who are not necessarily experts deeply involved in the field of risk management.

\section{Conclusions}

In the first chapter of our paper, we discussed the issue of calculating the VaR method generally. As researchers argue (Treapăt and Anghel, 2016) most of the banks that are key actors with big exposures to the market risk, have implemented complex risk indicators and instruments for evaluating the impact of the risk upon the activity, tools that can be applied to different markets. Although the specific arrangements may differ, these internal evaluation models are usually framing into common conceptual scenery. Typically, these models are evaluating the aggregated exposure to the market risk a bank has and, given the probability level, they estimate the amount that the bank would lose if it owned certain assets for a certain period of time. As such models, relying on VaR cover a series of market risks, the bank may ,adjust" its portfolio's structure, by choosing from a series of options for diversifying its portfolio, for reducing the risk it is exposed to and/or the associated capital requirements. The data that are the input in the VaR based model comprise information about the bank's positions and the prices, the volatility and their risk factors such as the term of the assets. The data must be comprehensive enough for illustrating all the risks that are incidental to the bank's balance sheet positions and to the positions outside the bank's balance sheet. All the risks that are covered by the model must include all the positions related to the interest, foreign currency rate, shares, commodities and to the options in the bank's portfolio.

In the second chapter, we elaborated the methods used. We focused on the calculation of normal linear VaR and scaling VaR. In the next chapter, we then described and compiled our proposed calculation formulas for calculating $\mathrm{VaR}$, which resulted in a level of significance. We then compiled the regression models for each calculation formula separately and interpreted the results. In the fourth chapter, we then interpreted, described, and discussed the results obtained. Based on this research, we consider the goal of the study to have been met, and believe that our results will be a valuable contribution to the field of research on this issue.

The advantages that the VaR estimation offers, consist of its ability to quantitatively and numerically express the risk level of a portfolio, at a certain moment in time and also the risk of on open position (in titles, in FX, commodities or granted loans), belonging to an economic agent or even individual. Hence, its role in a more efficient capital allocation, in the assumed risk delimitation, and also as a performance measurement instrument. In this paper and the study case that completes our work, we aim to prove how we can prevent considerable losses and even bankruptcies if $\mathrm{VaR}$ is known and applied accordingly. For this reason, the universities in Eastern Europe should include or increase their curricula with the study of the $\mathrm{VaR}$ model as an artificial intelligence tool. If we try to express some conclusions, which 
some researchers specializing in VaR models have also shown (Treapăt and Gheorghiu, 2017) we believe that studying the mathematical models profoundly in universities and not only using them in financial institutions, we should be able to shape and stimulate aspects of cognition to our students. This way, we learn how to create systems of thinking that mimic econometric systems, as well as how to use theoretical insights for a better understanding of the cognitive processing in the human brain.

Author contributions: All authors listed have made a substantial, direct and intellectual contribution to the work, and approved it for publication.

Data Availability Statement: The data presented in this study are available on request from the corresponding author. The data are not publicly available due to own empirical research of corresponding author.

Conflicts of Interest: The authors declare no conflict of interest.

\section{References}

Agliardi, R. (2018). Value-at-risk under ambiguity aversion. Financial Innovation, 4(1).

Ahmadi-Javid, A., \& Fallah-Tafti, M. (2019). Portfolio optimization with entropic value-at-risk. European Journal of Operational Research, 279(1), 225-241.

Alexander, C. (2008). Market Risk Analysis Volume IV, Value-at-Risk Models. John Wiley \& Sons Ltd, The Atrium, Southern Gate, Chichester, West Sussex PO19 8SQ, England.

Bi, J., \& Zhu, YF. (2020). Value at risk, cross-sectional returns and the role of investor sentiment. Journal of Empirical Finance, 56, 1-18,

Brandi, G., \& Di Matteo, T. (2021). On the statistics of scaling exponents and the multiscaling value at risk. European Journal of Finance.

Bucher, A., Posch, P. N., \& Schmidtke, P. (2020). Using the extremal index for value-at-risk backtesting. Journal of Financial Econometrics, 18(3), 556-584.

Butler, J. S., \& Schachter, B. (1996). Estimating Value-at-Risk with a precision measure by combining kernel estimation with historical simulation, Chase Manhattan Bank, 6th Floor, 270 Park Avenue, New York.

Cisko, S., \& Kliestik, T. (2013). Financial management of enterprises ( $2^{\text {nd }}$ edition), EDIS, Zilina.

Corbetta, J., \& Peri, I. (2018). Backtesting lambda value at risk. European Journal of Forecasting, 24(13), 10751087.

Crespi, G. P., \& Mastrogiacomo, E. (2020). Qualitative robustness of set-valued value-at-risk. Mathematical Methods of Operations Research, 91(1), 25-54.

Del Brio, E. B., Mora-Valencia, A., \& Perote, J. (2020). Risk quantification for commodity ETFs: Backtesting value-at-risk and expected shortfall. International Review of Financial Analysis, 70.

Dong, Y. C., Hu, Y. J., \& Feng, Y. (2020). Set-valued weighted value at risk and its computation. Frontiers in Physics, 8.

Echaust, K., \& Just, M. (2020). Value at risk estimation using the garch-evt approach with optimal tail selection. Mathematics, 8(1), 114.

Embrechst, P., Lindskog, F., \& McNeil, A. (2001). Modelling Dependence with Copulas and Applications to Risk Management, Department of Mathematics, ETHZ, CH-8092 Zurich, Switzerland.

Halkos, G. E., \& Tsirivis, A. S. (2019). Value-at-risk methodologies for effective energy portfolio risk management. Economic Analysis and Policy, 62, 197-212.

Holton, G. (2003). Value-at-Risk: Theory and Practice. Academic Press, New York.

Chen, Y, Wang, Z. C., \& Zhang, Z. J. (2019). Mark to market value at risk. Journal of Econometrics, 208(1), 299-321.

Jorion, P. (2001). Value at Risk: The New Benchmark for Managing Financial Risk, (2 ${ }^{\text {nd }}$ edition), In: McGrawHill Trade, New York. 
Josaphat, B. P., \& Syuhada, K. (2021). Dependent conditional value-at-risk for aggregate risk models. Heliyon, $7(7)$.

Kabaila, P., \& Mainzer, R. (2018). Estimation risk for value-at-risk and expected shortfall. Journal of Risk, 20(3), 29-47.

Le, T. H. (2020). Forecasting value at risk and expected shortfall with mixed data sampling. International Journal of Forecasting, 36(4), 1362-1379.

Leippold, M., \& Vasiljevic, N. (2020). Option-implied intrahorizon value at risk. Management Science, 66(1), $397-414$

Liu, W., Semeyutin, A., Lau, C. K. M., \& Gozgor, G. (2020). Forecasting value-at-risk of cryptocurrencies with riskmetrics type models. Research in International Business and Finance, 54.

Meng, X. C., \& Taylor, J. W. (2020). Estimating value-at-risk and expected shortfall using the intraday low and range data. European Journal of Operational Research, 280(1), 191-202.

Mitic, P., Cooper, J., \& Bloxham, N. (2020). Incremental value-at-risk. Journal of Risk Model Validation, 14(1), 65-101.

Molino, A., \& Sala, C. (2021). Forecasting value at risk and conditional value at risk using option market data. Journal of Forecasting, 40(7), 1190-1213.

Rige, G., Wirjanto, T., \& Zhao, YQ. (2020). Forecasting value at risk with intra-day return curves. International journal of forecasting, 36(3), 1023-1038.

Silahli, B., Dingec, K. D., Cifter, A., \& Aydin, N. (2021). Portfolio value-at-risk with two-sided Weibull distribution: Evidence from crypto currency markets. Finance research letters, 38, 101425.

Slim, S., Dahmene, M., \& Boughrara, A. (2020). How informative are variance risk premium and implied volatility for Value-at-Risk prediction? International evidence. Quarterly Review of Economics and Finance, $76,22-37$.

Tan, Z. X., Huang, Y. L., \& Xiao, B. U. (2021). Value at risk and returns of cryptocurrencies before and after the crash: long-run relations and fractional cointegration. Research in International Business and Finance, $56,101347$.

Thavaneswaran, A., Paseka, A., \& Frank, J. (2020). Generalized value at risk forecasting. Communications in Statistics-Theory and Methods, 49(20), 4988-4995.

Treapăt, L.-M., \& Anghel, L. C. (2016). Managing the market risk in banks. strategica. Management, Finance, and Ethics. București: Tritonic.

Treapăt, L.-M., \& Gheorhiu, A. (2017). Artificial systems and models for risk covering operations. Broad research in Artificial and Neuroscience, $8(1)$.

Zhang, W. B., Zhang, S., \& Zhao, P. B. (2019). On double value at risk. Risks, 7(1). 